\title{
Management of Chronic Pacemaker Lead Infection, Superior Vena Cava Obstruction and Tricuspid Valve Endocarditis (Operative Technique and a Case Report)
}

\author{
Husain H. Jabbad, FRCSC \\ Department of Surgery, Division of Cardiothoracic Surgery \\ King Abdulaziz University, Jeddah, Saudi Arabia
}

\section{Correspondence}

Dr. Husain H. Jabbad

Department of Surgery,

Division of Cardiothoracic Surgery

King Abdulaziz University

P.O. Box 80215, Jeddah 21589, Saudi Arabia

e.M: hjabbad@kau.edu.sa

Submission: 25 August 2014

Accepted: 24 November 2014

\section{Citation}

Jabbad HH. Management of chronic

pacemaker lead infection, superior vena cava

obstruction and tricuspid valve endocarditis

(operative technique and a case report). JKAU

Med Sci 2015; 22(1): 45-51.

\begin{abstract}
A 73 year old female presented with the diagnosis of infected cardiac pacemaker. She had complete heart block 2.5 years ago, a permanent dual chamber pacemaker was inserted via a left subclavian approach and the pulse generator positioned in the left clavipectoral fascia. In the early post operative period she developed fever with a clear pacemaker pocket infection, treated with intravenous antibiotics. The initial pacemaker was removed, the pocket cleaned and closed and a new dual-chamber pacemaker inserted in the right clavipectoral area via right subclavian approach. She was kept on a prolonged antibiotics course of vancomycin and gentamicin because of sepsis and blood cultures results of Pseudomonas aeruginosa. On presentation she had diabetes insipidus, recurrent low grade fever and impaired renal function, the pacemaker was functioning well and she was still on IV vancomycin. Investigations revealed a large intra-atrial clot attached to the pacemaker lead, the pacemaker and infected intravascular component were removed via median sternotomy and new pacemaker inserted with epicardial atrial and ventricular leads. The intra-operative cultures grow Pseudomonas aeruginosa treated with 6 weeks of intravenous Tazocin, follow-up for 9 months with no recurrent pocket or deep infection and good functioning pacemaker.
\end{abstract}

\section{Keywords}

Infective endocarditis, Cardiac pacemakers, Infection of cardiac implantable electronic devices.

\section{Introduction}

nfection of cardiovascular implantable electronic device (CIED) is a serious complication of pacemaker insertion surgery. It has been reported in a number of observational series, but its true incidence is difficult to determine due to the lack of comprehensive registry or mandatory reporting ${ }^{[1,2]}$.

CIED infection can be considered in two categories: pocket infection or deeper infection. Pocket infection is when the infection involves the subcutaneous pocket containing the device and the subcutaneous segment of the leads. Deeper infection is when the infection involves the transvenous portion of the lead that is usually with associated bacteremia and/or endovascular infection $^{[3]}$.

CIED infection can also be classified according the mode of infection as primary or secondary. Primary infection is when the device and/or pocket itself is the 
source of infection which is usually due to contamination at the time of implant. Secondary infection is when the leads (and then sometimes the device and the pocket) are seeded due to bacteremia from a different source ${ }^{[3]}$.

\section{Case Report}

The patient is a $73 \mathrm{yr}$ old female diagnosed to have complete heart block (CHB) 2.5 yrs ago, a permanent dual chamber )DDD) pacemaker was inserted via a left subclavian approach and the pulse generator positioned in the left clavipectoral area. In the early post-operative period she developed fever with a clear pacemaker

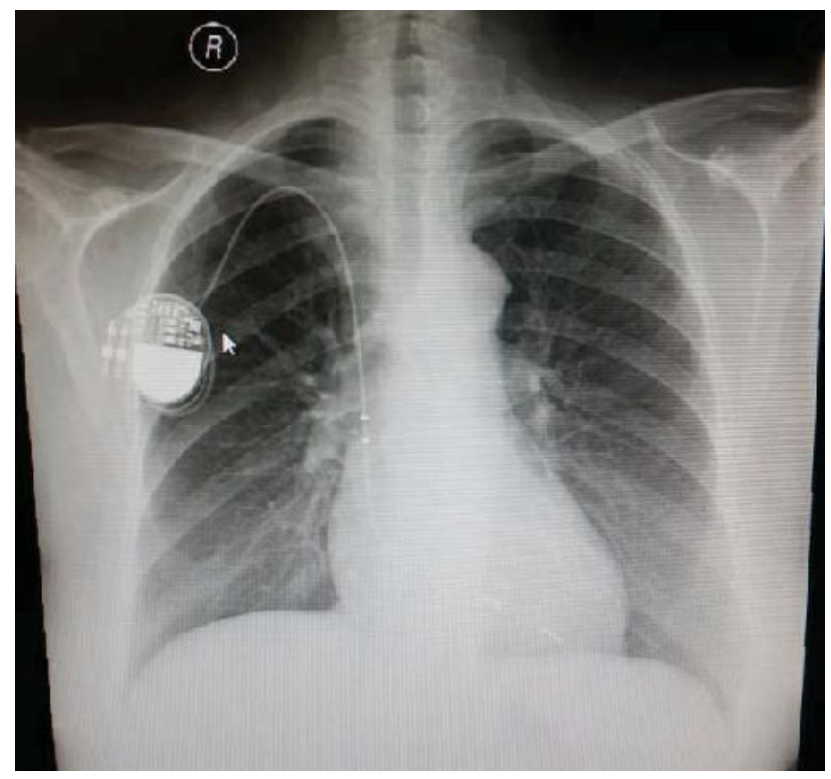

Figure 1. Preoperative chest X-ray - Posteroanterior.

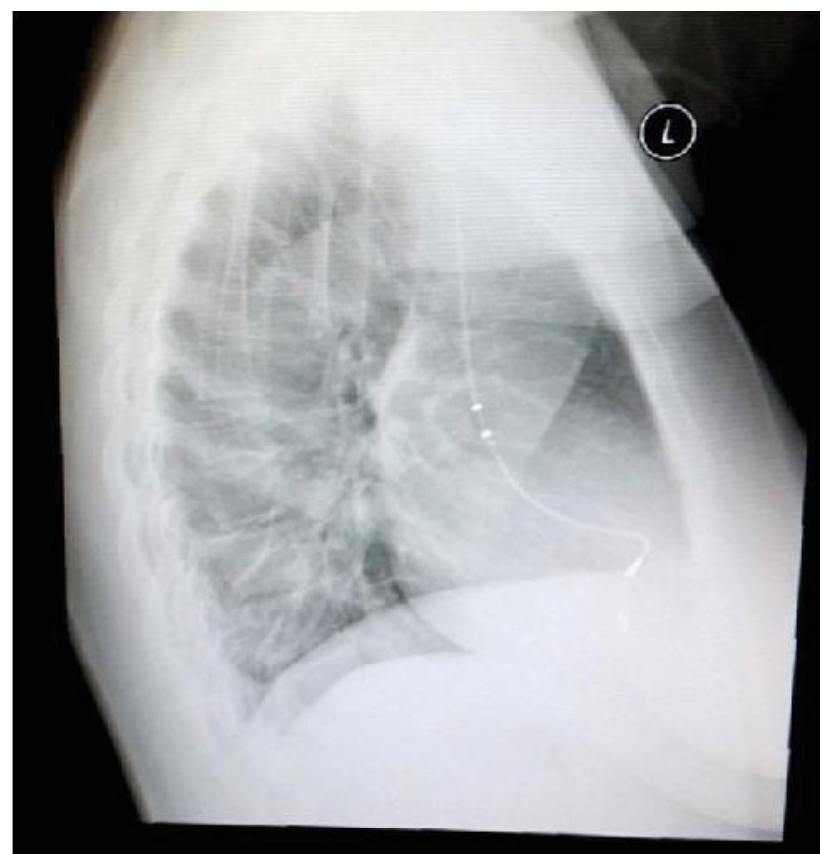

Figure 2. Preoperative chest X-ray - Lateral. pocket infection, treated with intravenous antibiotics. The initial pacemaker was removed, the pocket cleaned and closed and a new DDD pacemaker inserted in the right clavipectoral area via right subclavian approach and an infected pacemaker lead and prolonged treatment with intravenous antibiotics. She developed diabetes insipidus and renal impairment. On admission a detailed history and physical examination was obtained. Investigations included: complete blood count (white blood cells 11,700, hemoglobin 10.4, platelets 164,000); chest X-rays (Figs. 1, 2); 12-lead electrocardiogram (ECG) (demand pacing, well-functioning DDD pacing); the underlying heart rate without pacing checked by application of magnet (CHB 29 beats per minute); serum electrolytes (potassium 2.9 = corrected); normal urea and creatinine; normal liver function tests.

Transthoracic echocardiogram (TTE) revealed large clot adherent to the pacemaker lead in the right atrium causing moderate tricuspid valve incompetence (Fig. 3). Transesophageal echocardiogram (TEE) confirmed the findings, in addition to occlusion of the innominate vein and the upper superior vena cava (SVC) (Figs. 4, 5).

Blood cultures (aerobic, anaerobic and fungal) all negative prior to surgery.

Computed tomography (CT) scan of the chest revealed no evidence of pulmonary embolism, there was SVC-innominate vein junction obstruction.

The case was discussed in detail with the patient and her family and a preoperative informed consent obtained including the need for removal of the infected pacemaker lead and its pulse generator, the need for median sternotomy approach to remove the infected clot over the pacemaker lead in the right atrium,

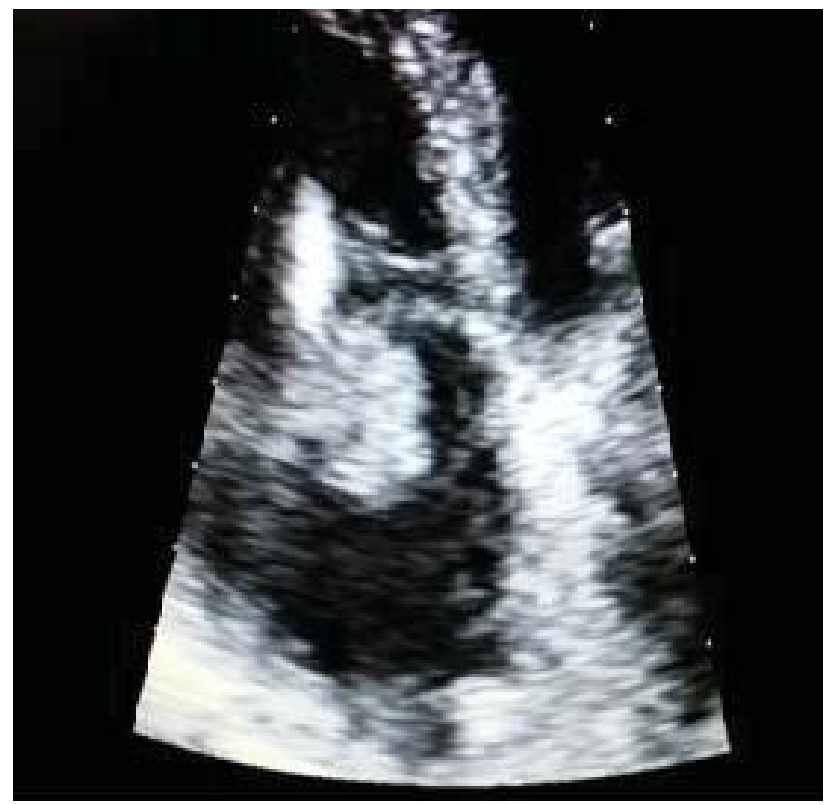

Figure 3. Preoperative transthoracic echocardiogram. 


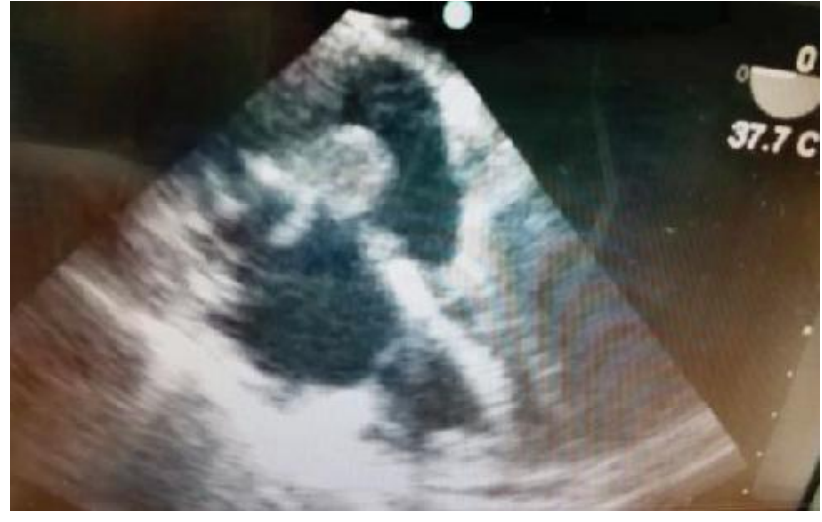

Figure 4. Preoperative transesophageal echocardiogram.

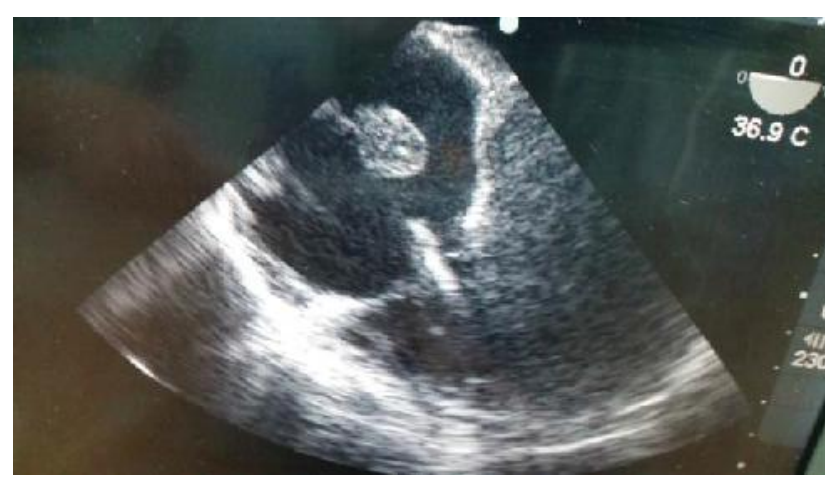

Figure 5. Preoperative transesophageal echocardiogram.

operative risks including the use of cardiopulmonary bypass, risk of pulmonary embolization, bleeding and sepsis and the need of postoperative antibiotics for 6-8 weeks.

\section{Operative Technique}

General anesthesia; patient on IV vancomycin; median sternotomy without the use of unipolar diathermy to avoid interfering with the permanent pacemaker; pericardiotomy and application of epicardial temporary pacing wires and start of pacing by an external pacemaker before the use of diathermy for hemostasis; exposure of the right common femoral vein. We then exposed the pulse generator in the right clavipectoral pocket and cleared the adhesions from the lead (Fig. 6), following full heparinization (activated clotting time (ACT) test $>3$ times initial), insertion of aortic cannula $\# 21 \mathrm{~F}$ in the ascending aorta and \#22 F long femoral venous cannula in the right common femoral vein. Extracorporeal cardiopulmonary bypass initiated and the inferior vena cava clamped at the right atrial junction. Right atriotomy performed on beating heart for removal of the pacemaker lead from the right ventricle and a complete removal of the infected clot from the lead. Vegetations on the anterior leaflet of the tricuspid valve were removed and the leaflet cleaned with vancomycin

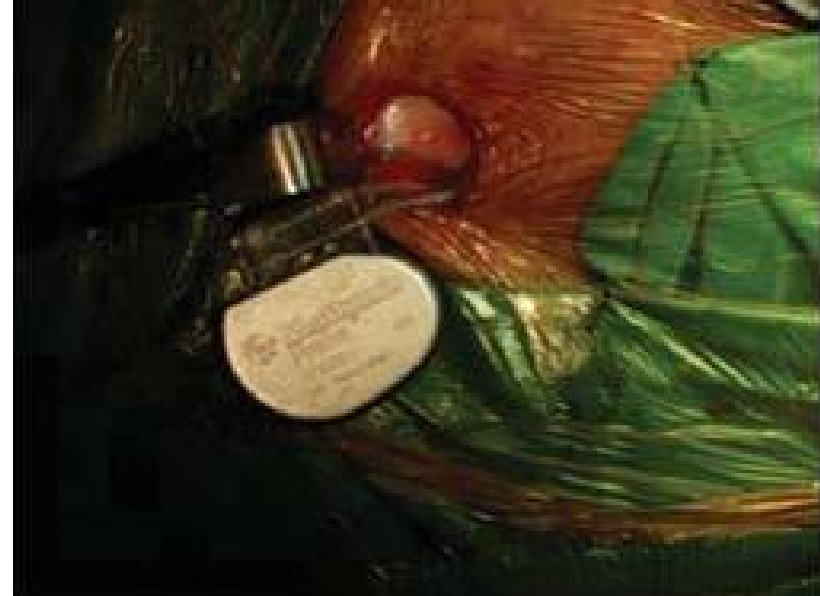

Figure 6. Intraoperative the old pacemaker extracted from the pacemaker pocket with no evidence of pocket infection.

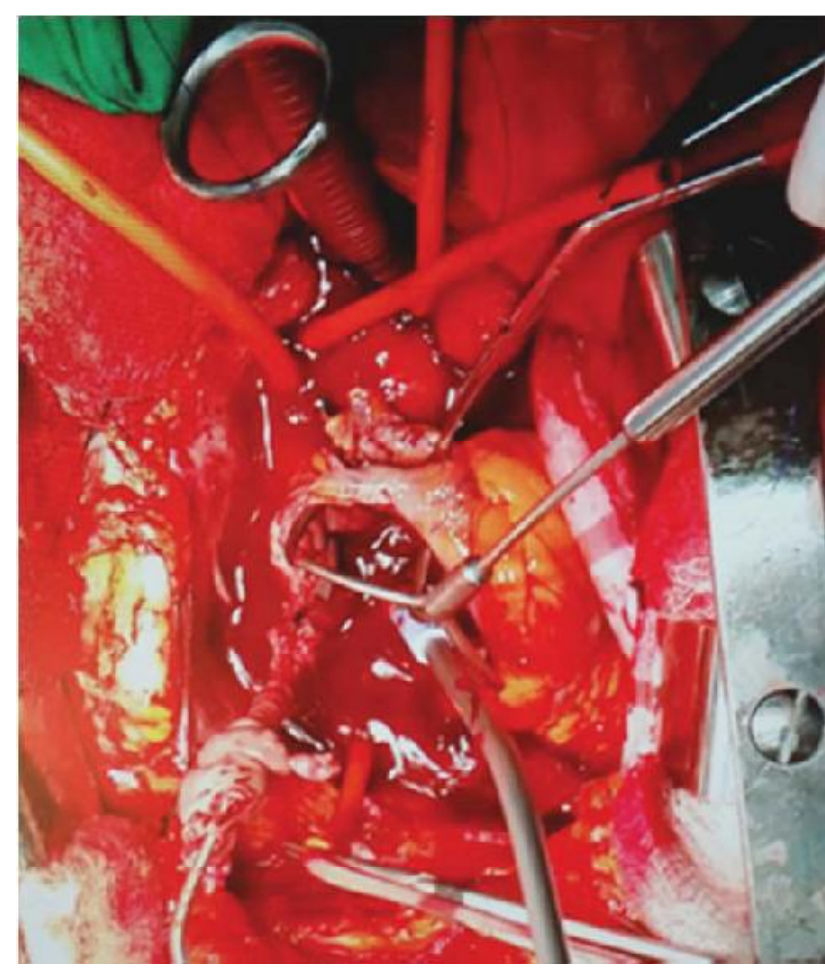

Figure 7. Intraoperative infected clots covering the intra atrial portion of the pacemaker lead.

solution (Figs. 7 and 8). Infected pacemaker lead clots were sent for bacterial and fungal cultures (Fig. 9). The pacemaker single lead pulled out from the clavipectoral pocket which was safer than pulling the two leads at the pulse generator end down.

The right atrial incision was closed using 3-0 monofilament non absorbable sutures. The clamps were removed and the patient weaned off cardiopulmonary bypass. Cannulae removed and the right femoral vein repaired. Protamine sulphate was given followed by closure of the pacemaker pocket and right groin incision. 


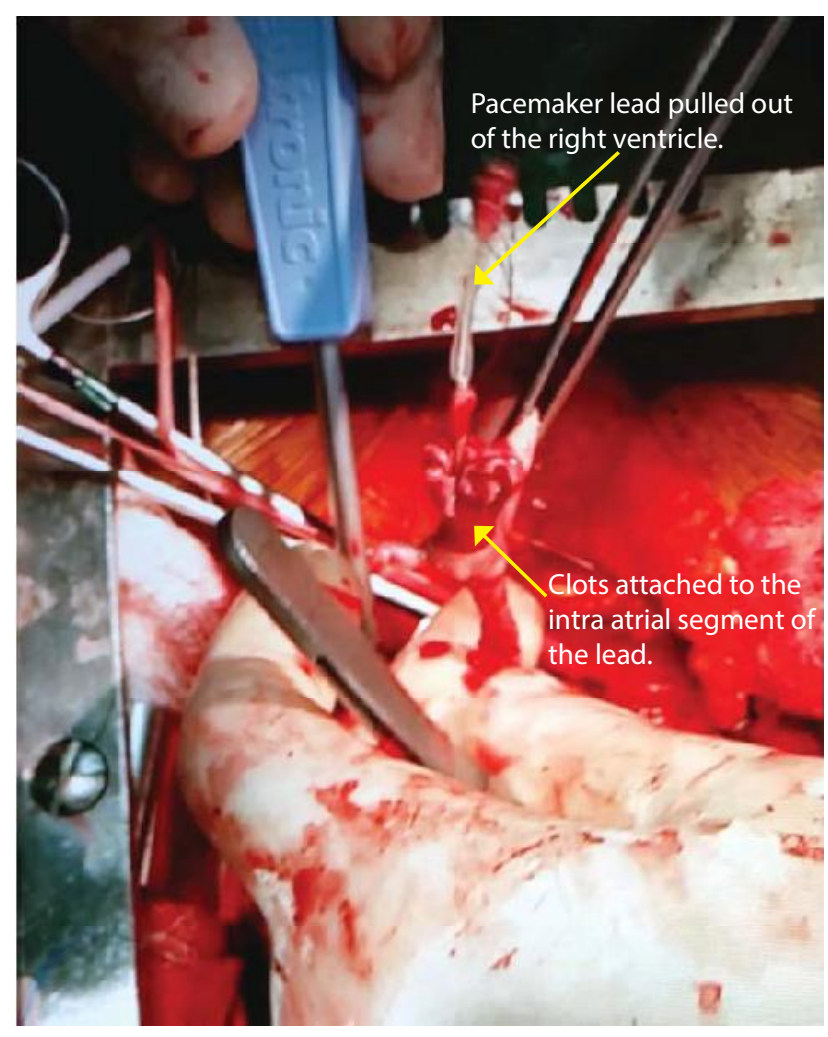

Figure 8. Intraoperative infected clots covering the intra atrial portion of the pacemaker lead after pulling the tip of the lead from the right ventricle.

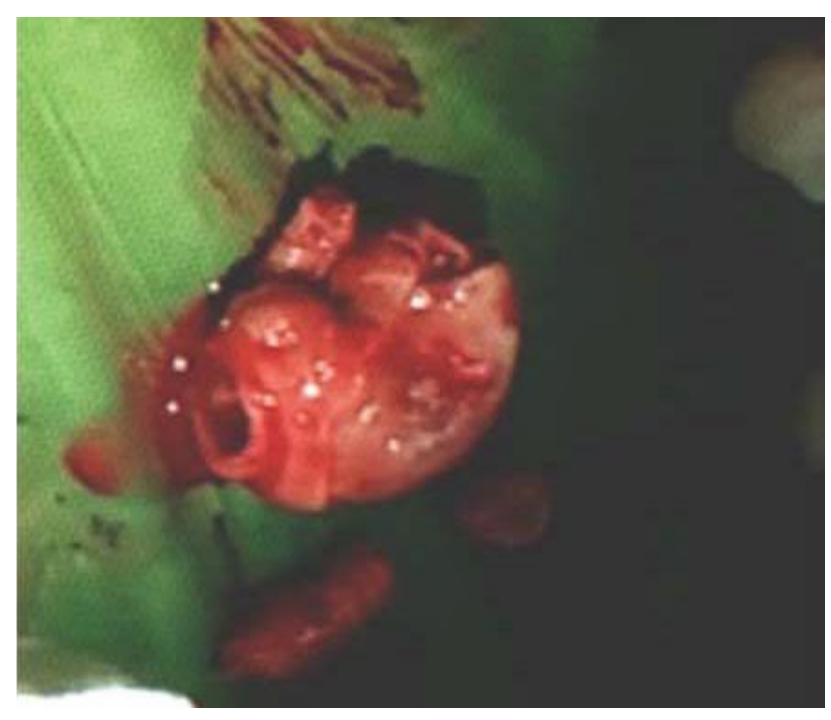

Figure 9. Intraoperative the infected clots after being removed from the pacemaker lead.

Two epicardial pacing wires applied/sutured to the right atrium and two epicardial pacing wires applied / sutured to the right ventricle (Fig. 10). A new pacemaker pocket was fashioned below the anterior rectus sheath via a transverse incision over the left rectus and the wires were passed to the left rectus abdominus pocket with the leads connected to a DDD pacemaker (Sensia ${ }^{\circ}$ Pacing System, Medtronic, Dublin, Ireland). Closure of

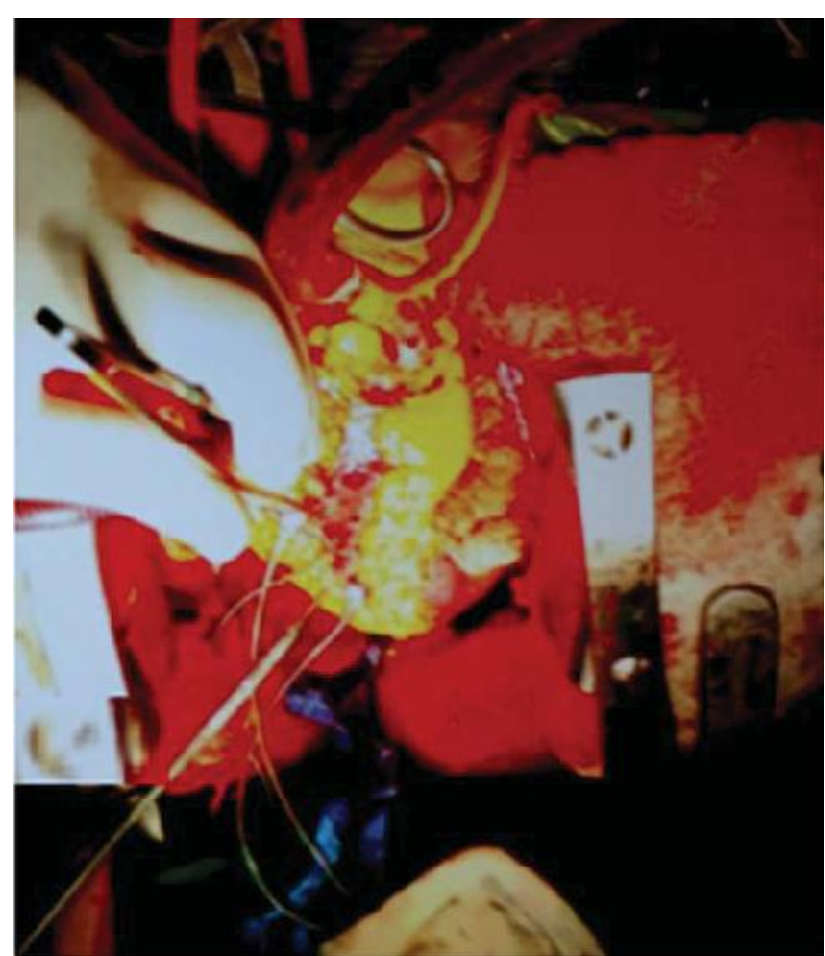

Figure 10. Epicardial pacing wires applied to the right atrium and the right ventricle.

the anterior rectus sheath, subcutaneous tissues and skin, insertion of mediastinal and pericardial chest tubes followed by closure of the median sternotomy.

Patient tolerated the procedure well and was transferred to the intensive care unit with no inotrope followed by early extubation (Fig. 11). She continued on IV vancomycin for 24 hours until the infected lead clot culture came back showing Pseudomonas aeroginosa sensitive to Tazocin. Vancomycin antibiotics changed to intravenous Tazocin which was then continued for 6 weeks.

Postoperative chest CT scan were the same with no evidence of pulmonary embolism (PE), still occluded SVC innominate vein junction (Figs. 11, 12).

It's suspected that her gram negative endocarditis, pacemaker lead infection and SCV obstruction are secondary to an early pocket infection, which seeded into the blood stream and that, with the insertion of the second pacemaker, its lead got infected from the previous extension of the intravascular infection.

The choice to use the epicardial atrial and ventricular leads was made to decrease the chance of recurrent endocarditis and because of the obstruction of the upper SVC.

\section{Discussion}

Factors that increase the risk of developing pacemaker infection include, recent manipulation of the 


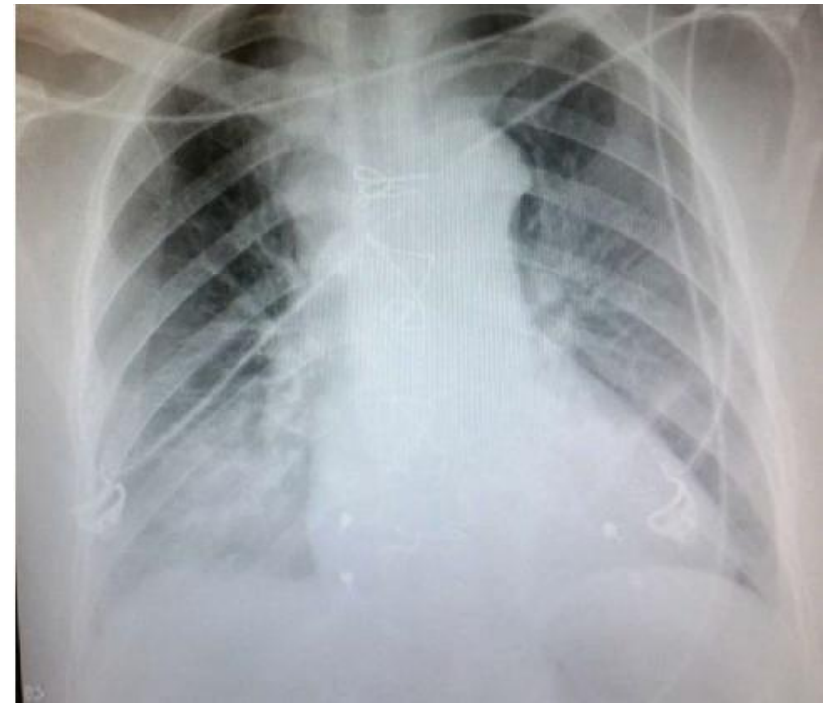

Figure 11. Postoperative chest X-ray - Posteroanterior.

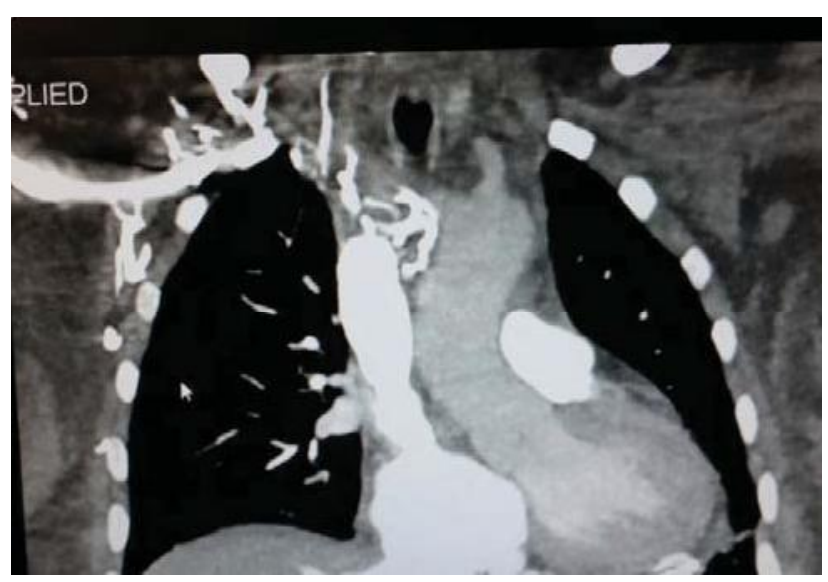

Figure 12. Postoperative chest CT scan.

device ${ }^{[2]}$, fever within $24 \mathrm{hr}$ before implantation, early intervention and use of intravenous temporary pacing before the implantation procedure ${ }^{[4]}$, renal dysfunction with glomerular filtration rate $<60 \mathrm{ml} / \mathrm{min}$, use of oral anticoagulation ${ }^{[5]}$, long term glucocorticoid therapy, and the presence of more than two pacing leads ${ }^{[6]}$.

In a retrospective cohort study in Minnesota by Ulsan et al. ${ }^{[7]}$ between 1975 and 2004, among 1524 device patients, the incidence of pacemakers definite infection was 1.0 per 1000 device-year. The incidence of definite device infection was 1.9 per 1000 device-years, the incidence of pocket infection without bloodstream infection was 1.37 per 1000 device-years, and pocket infection with bloodstream infection or device-related endocarditis 1.14 per 1000 device years. The cumulative probability of device infection was higher among patients with defibrillators compared with those with pacemakers (54.6\% vs. $12.0 \%)$. The causative organism was Staphylococcus aureus infection in $88 \%$ and gramnegative bacilli bloodstream infection in $12 \%{ }^{[7]}$.
In 2007 Klug et al. ${ }^{[4]}$ reported a prospective study of 6319 consecutive recipients of pacemakers or ICDs in 44 medical centers in France during the year 2000 and 12 months of follow-up: the rate of infection was 0.68 per 100 patients and infection plus erosions were noted in 1.19 per 100 patients $^{[4]}$.

Deep infection of the intra vascular component of pacemaker occurs in the intra-cardiac portion of the lead along the right atrium, the tricuspid valve, or in the right ventricular contact point. It may be due to intravascular tracking from pocket and subcutaneous tissues infection or may arise from bacteremia seeding from a remote site $^{[8,9]}$.

Endocarditis secondary to deep / pacemaker lead infections is caused by staphylococcus infection in most cases $^{[11]}$. In 1997 Klug et al. ${ }^{[8]}$ reported 52 patients with $93.5 \%$ caused by staphylococcus organism, 70\% of the patients presented in a chronic stat with fever in $86.5 \%$, elevated C-reactive protein in $96.2 \%$, pulmonary infarction in $31.2 \%$ and a germ was isolated in $88.4 \%$. TTE demonstrated vegetations in only $23 \%$ of patients, whereas TEE disclosed abnormal appearances on the PM lead in $94 \%{ }^{[8]}$.

In patients receiving CIED, long-term survival was significantly reduced with CIED infection $(71.6 \%$ vs. $85.0 \%, p<0.001)$. Among patients with CIED infection, women had substantially reduced long-term survival compared with men $(67.3 \% \text { vs. } 72.9 \%, p<0.02)^{[11]}$.

The prompt removal of all the CIED hardware with prolonged parenteral antibiotic administration decrease mortality among patients with infected CIED. The presence of a large ( $>10 \mathrm{~mm}$ in diameter) vegetation on a lead is not a contraindication for percutaneous lead extraction $^{[12]}$.

CIED infections continue to occur and can be lifethreatening despite the improvements in its design, application of timely infection control practices, and administration of antibiotic prophylaxis at the time of device placement ${ }^{[13]}$.

\section{References}

[1] Arber N, Pras E, Copperman Y, Schapiro JM, Meiner V, Lossos IS, Militianu A, Hassin D, Pras E, Shai A, et al. Pacemaker endocarditis. Report of 44 cases and review of the literature. Medicine (Baltimore) 1994; 73(6): 299-305.

[2] Eggimann P, Waldvogel F. Pacemaker and defibrillator infections. In: Infections Associated with Indwelling Medical Devices. Waldvogel FA, Bisno AL (eds), Washington, DC: Am Soc Microbiol P, 2000. 247.

[3] Baddour LM, Cha YM, Wilson WR. Clinical practice. Infections of cardiovascular implantable electronic devices. N Engl J Med 2012; 367(9): 842-849.

[4] Klug D, Balde M, Pavin D, Hidden-Lucet F, Clementy J, Sadoul N, Rey JL, Lande G, Lazarus A, Victor J, Barnay C, Grandbastien 
B, Kacet S; PEOPLE Study Group. Risk factors related to infections of implanted pacemakers and cardioverterdefibrillators: results of a large prospective study. Circulation 2007; 116(12): 1349-1355.

[5] Lekkerkerker JC, van Nieuwkoop C, Trines SA, van der Bom JG, Bernards A, van de Velde ET, Bootsma M, Zeppenfeld K, Jukema JW, Borleffs JW, Schalij MJ, van Erven L. Risk factors and time delay associated with cardiac device infections: Leiden device registry. Heart 2009; 95(9): 715-720.

[6] Sohail MR, Uslan DZ, Khan AH, Friedman PA, Hayes DL, Wilson WR, Steckelberg JM, Stoner SM, Baddour LM. Risk factor analysis of permanent pacemaker infection. Clin Infect Dis 2007; 45(2): 166-173.

[7] Uslan DZ, Sohail MR, St Sauver JL, Friedman PA, Hayes DL, Stoner SM, Wilson WR, Steckelberg JM, Baddour LM. Permanent pacemaker and implantable cardioverter defibrillator infection: a population-based study. Arch Intern Med 2007; 167(7): 669-675.

[8] Klug D, Lacroix D, Savoye C, Goullard L, Grandmougin D, Hennequin JL, Kacet S, Lekieffre D. Systemic infection related to endocarditis on pacemaker leads: clinical presentation and management. Circulation 1997; 95(8): 2098-21007.

[9] Camus C, Leport C, Raffi F, Michelet C, Cartier F, Vilde JL. Sustained bacteremia in 26 patients with a permanent endocardial pacemaker: assessment of wire removal. Clin Infect Dis 1993; 17(1): 46-55.

[10] Chamis AL, Peterson GE, Cabell CH, Corey GR, Sorrentino RA, Greenfield RA, Ryan T, Reller LB, Fowler VG Jr. Staphylococcus aureus bacteremia in patients with permanent pacemakers or implantable cardioverter-defibrillators. Circulation 2001; 104(9): 1029-1033.

[11] Sohail MR, Henrikson CA, Braid-Forbes MJ, Forbes KF, Lerner DJ. Comparison of mortality in women versus men with infections involving cardiovascular implantable electronic device. Am J Cardiol 2013; 112(9): 1403

[12] Sohail MR, Uslan DZ, Khan AH, Friedman PA, Hayes DL, Wilson WR, Steckelberg JM, Jenkins SM, Baddour LM. Infective endocarditis complicating permanent pacemaker and implantable cardioverter-defibrillator infection. Mayo Clin Proc 2008; 83(1): 46-54.

[13] Baddour LM, Epstein AE, Erickson CC, Knight BP, Levison ME, Lockhart PB, Masoudi FA, Okum EJ, Wilson WR, Beerman LB, Bolger AF, Estes NA 3rd, Gewitz M, Newburger JW, Schron EB, Taubert KA; American Heart Association Rheumatic Fever, Endocarditis, and Kawasaki Disease Committee; Council on Cardiovascular Disease in Young; Council on Cardiovascular Surgery and Anesthesia; Council on Cardiovascular Nursing; Council on Clinical Cardiology; Interdisciplinary Council on Quality of Care; American Heart Association. Update on cardiovascular implantable electronic device infections and their management: a scientific statement from the American Heart Association. Circulation 2010; 121(3): 458-477. 


\title{
علاج عدوى مزمنة لأسلاك منظم ضربات القّلب مصحوب بإنسداد الوريا

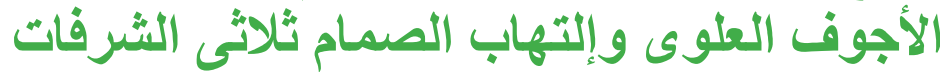

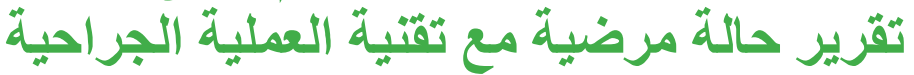

\author{
حسين حمزة جباد

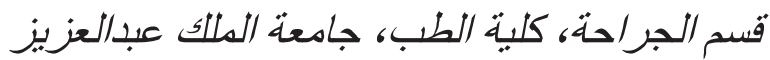 \\ جلة ـ المدلكة العربية السعودية كلية
}

المستخلص. المريضة تبلغ من العمر VT عاما أصيبت قبل عامين ونصف بإنسداد كامل للضفيرة القلبية وتم تركيب منظم

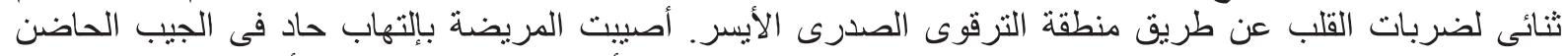

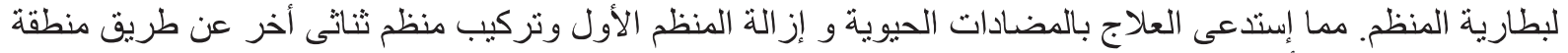

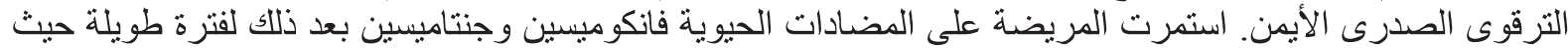

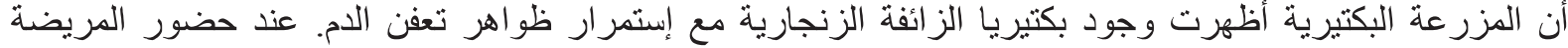

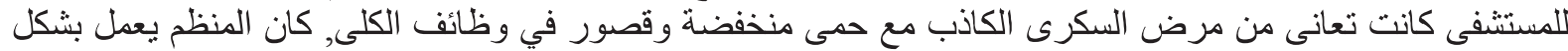

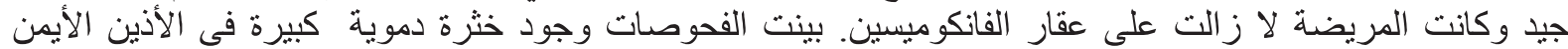

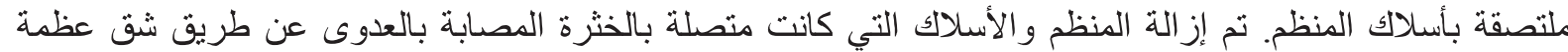

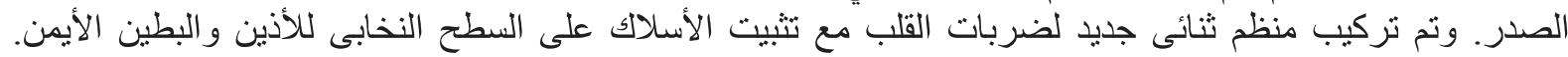

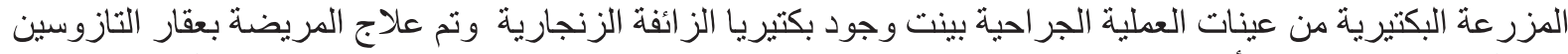

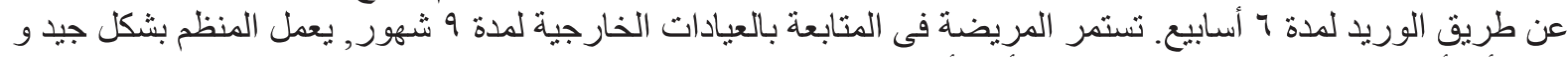

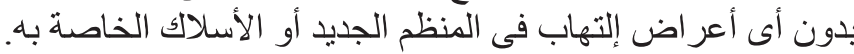

